\title{
The Return due to Diversification of Real Estate to the US Mixed-Asset Portfolio
}

\author{
A Paper Presented at the $10^{\text {th }}$ Annual \\ European Real Estate Society (ERES) Meeting \\ Helsinki Finland \\ June, 2003 \\ Stephen L. Lee \\ Centre for Real Estate Research (CRER) \\ School of Business, The University of Reading \\ Reading, RG6 6AW \\ England
}

Phone: +44 118378 6338, Fax: +44 118378 8172, E-mail: S.L.Lee@ reading.ac.uk

\begin{abstract}
Booth and Fama (1992) observe that the compound return and so the terminal wealth of a portfolio is greater than the weighted average of the compound returns of the individual investments, a difference referred to as the return due to diversification (RDD). Thus assets that offer high RDD should be particularly attractive investments. This paper test the proposition that US direct real estate is such an asset class using annual data over the period 1951-2001. The results show that adding real estate to an existing mixed-asset portfolio increases the compound return and so the terminal wealth of the fund. However, the results are dependent on the percentage allocation to real estate and the asset class replaced.
\end{abstract}

Keywords: Real Estate, compound return and return due to diversification. 


\section{The Return Due to Diversification of Real Estate in the Mixed-asset Portfolio}

\section{Introduction}

The argument for including real estate in the mixed-asset portfolio is typically made on its diversification benefits rather than on its contribution to the return of the portfolio. Indeed, in a recent paper Hudson-Wilson and Hopkins (2000) finds that the private real estate market in the US offered investors such poor performance compared with either stocks or bonds that the authors can see little case for real estate in the mixed-asset portfolio. The argument of Hudson-Wilson and Hopkins (2000) can be criticised on at least three counts. First, the data used only covers the period 1990 to 2000, a period of spectacular growth in the performance of shares on the back of the Dotcom boom, which is unlikely to be representative of performance of stocks in the long run. The recent reversal in shares since 2001 testifies to this. Yet it is the long-run returns investors need to examine in deriving the strategic asset allocation (SAA) of the mixed-asset portfolio. Second, when an investor is contemplating the addition of an asset to the mixed-asset portfolio they need to consider the contribution the asset makes to the risk and return of the portfolio as a whole rather than its individual risk and return characteristics. Third, institutional investors should be more concerned with the terminal wealth of their portfolio of investments rather than the individual assets past performance, as it is from the terminal wealth of the fund that the institutional will meet its future contractual obligations (Radcliffe, 1994). Thus, for those institutional with long-run holding periods the terminal wealth or compound return should be seen as the primary measurement of performance. Hence, assets that contribute most to the compound return, or terminal wealth, of the mixed-asset portfolio should present the greatest attraction to institutional investors. Hence, when deciding on the SAA of the mixed-asset portfolio investors should focus their attention on those assets that contribute most to the compound return of the mixed-asset portfolio.

However, this does not mean that investors should concentrate their holdings in assets with the highest expected returns. Booth and Fama (1992) show that although the compound return of an investment (asset or portfolio) is an increasing function of its expected return, it is also a decreasing function of its risk (variance). In other words, investments with higher expected returns and high risks do not necessarily provide higher compound returns to the portfolio, than investments with lower expected returns and lower risks. Moreover, Booth and Fama (1992) show that the compound return of a portfolio is greater than the weighted average of the individual compound returns of the investments. Booth and Fama (1992) refer to this difference as the "return due to diversification" (RDD) of the investment within the portfolio. This counterintuitive result stems from the fact that although variance is an appropriate measure of risk of a portfolio it is not the relevant measure of the risk of the investment within a portfolio. The risk of an investment in a portfolio should be measured by its covariance with the portfolio. Thus, an asset with a low expected return but a low covariance may be more desirable, in terms of the compound returns of the portfolio, than an asset with a higher expected return but a high covariance. Previous studies find that real estate is an asset 
that displays good returns and low covariance with the mixed-asset portfolio (see Seiler et al, 1999 and Hoesli et al, 2001 for comprehensive reviews). Consequently, a large holding of real estate in the mixed-asset portfolio may be justifiable on its compound return enhancing effect on the mixed-asset portfolio and not simply on its risk reducing ability. This paper tests this proposition using annual returns in the US over the period 1951 to 2001 and finds that real estate can indeed justify a higher holding in the mixedasset portfolio than its individual compound return would suggest.

The remainder of the paper is organised as follows. The next section outlines the method of Booth and Fama (1992) for estimating the RDD of an investment within a portfolio. Section three discusses the data. Initial results are presented and discussed in section four. In section five the impact of the uncertainty of returns is examined. The final section concludes the paper.

\section{Return Due to Diversification}

Booth and Fama (1992) show that the compound return (C) of an investment (asset or portfolio) can be estimated by the following equation ${ }^{1}$ :

$$
C=\ln [1+E(R)]-s^{2} / 2[1+E(R)]
$$

where: $E(R)$ is the expected return of the investment, $s^{2}$ is the variance (standard deviation squared) of the investment's simple returns, and $\ln (1+\mathrm{E}(\mathrm{R})]$ is the average continuously compounded return of the investment. Equation 1 says that the compound return of an investment is an increasing function of its expected return but a decreasing function of its variance. So, in the long run, investments with higher expected returns will have greater compound returns, or terminal wealth, holding risk (variance) constant. Alternatively, an investment with a low variance will have a higher compound return, compared with an investment with a higher variance but with the same expected return. However, although variance is an appropriate measure of risk of an individual investment it is not the relevant measure of the risk of an investment within a portfolio.

Modern portfolio theory shows that the risk of an asset in a portfolio should be measured by its contribution to the risk of the portfolio and that this risk should be measured by its covariance with the portfolio. The lower the covariance of an investment with a portfolio, the higher its contribution to reducing the risk of the portfolio, and so the greater the attractiveness of the investment to the portfolio. Booth and Fama (1992) show that it is this insight that explains why the contribution of an asset to the compound return of a portfolio is greater than the weighted average of the individual compound returns.

The covariance of an investment $\mathrm{j}$ with a portfolio $\mathrm{p}$ can be expressed by the following:

\footnotetext{
As Booth and Fama (1992) acknowledge this is only an approximation, as higher moments from the Taylor expansion are ignored. Nonetheless, the authors show that the difference between the actual compound return and that estimated using equation 1 is minuscule, especially the longer the estimation period.
} 


$$
\operatorname{Cov}\left(R_{j}, R_{p}\right)=\beta_{j p} s_{p}^{2}
$$

where: $\operatorname{Cov}\left(R_{j}, R_{p}\right)$ is the covariance of investment $j$ with portfolio $p, \beta_{j p}$ (beta) is a measure of the investments $\mathrm{j}$ relative, or systematic risk, with portfolio $\mathrm{p}$ and $\mathrm{s}_{\mathrm{p}}^{2}$ is the variance of portfolio $p$ the square of the standard deviation (s).

Booth and Fama (1992) then show that a very good approximation of the compound return of an investment within portfolio $p$, or its "return contribution", can be estimated by equation 3 :

$$
R C_{j}=E\left(R_{j}\right) \ln \left[1+E\left(R_{p}\right)\right] / E\left(R_{p}\right)-\beta_{j p} s_{p}^{2} / 2\left[1+E\left(R_{p}\right)\right]^{2}
$$

where $R C_{j}$ is the return contribution of investment $j$ to portfolio $p$, and $E\left(R_{p}\right)$ is the expected return of the portfolio. Comparing equation (3) with equation (1) shows that the compound return of an investment within a portfolio is not the same as its individual compound return, where the difference represents the RDD of the investment within the portfolio. In other words, the contribution of an investment to the compound return of a portfolio is greater than its individual compound return. Thus, those assets that show the greatest RDD should show the greatest contribution to the compound return of the portfolio.

\section{Data}

The mixed-asset portfolio considered in this study is made up of the annual returns of five asset classes: direct real estate, large cap stocks, small cap stocks, Government bonds and cash (T-Bills) covering the period 1951-2001. The data apart from the returns of real estate taken from Ibbotson Associates (2002), while the returns to real estate are taken from Kaiser (1997), with additions from NCRIEF. The summary statistics for these data series are shown in Table 1 from 1952-2001².

Table 1: Summary Statistics for Real Estate, Large Cap Stocks

\begin{tabular}{|c|c|c|c|c|c|c|}
\hline Statistics & Real Estate & Real Estate & Large Cap & Small Cap & Bonds & T-bills \\
\hline Mean & 9.948 & 9.751 & 13.286 & 17.080 & 6.648 & 5.328 \\
\hline Std. Dev. & 5.110 & 9.949 & 17.086 & 25.096 & 10.911 & 2.835 \\
\hline Skewness & -0.402 & 0.049 & -0.084 & 0.265 & 0.997 & 0.968 \\
\hline Kurtosis & 4.956 & 4.535 & 2.461 & 2.777 & 3.770 & 4.091 \\
\hline Jarque-Bera & 9.316 & 4.926 & 0.665 & 0.689 & 9.516 & 10.291 \\
\hline Probability & 0.009 & 0.085 & 0.717 & 0.708 & 0.009 & 0.006 \\
\hline $1^{\text {st }}$ Order & 0.624 & 0.030 & -0.086 & -0.043 & -0.074 & 0.835 \\
\hline $2^{\text {nd }}$ Order & 0.004 & 0.003 & -0.245 & -0.187 & 0.151 & -0.145 \\
\hline $3^{\text {rd }}$ Order & 0.022 & 0.159 & 0.026 & 0.033 & 0.199 & 0.075 \\
\hline
\end{tabular}
Small Cap Stocks, Bonds and Cash: 1952-2001

\footnotetext{
2 The reason for only considering the summary statistics from 1952 is that the first observation (1951) is lost in the desmoothing process used below.
} 
An examination of Table 1 indicates that small cap stocks had the highest risk (standard deviation) $25.1 \%$ per annum, over this period, but compensated investors with the highest mean returns $17.12 \%$, coefficient of variation of 1.47 . Real estate, in contrast, showed a much lower level of return $9.9 \%$ per annum, but at a significantly lower risk $5.1 \%$, coefficient of variation of 1.00 . Indeed, the risk of real estate is less than half that of government bonds, $10.9 \%$ per annum. The other important difference between the real estate returns and the other asset classes are its skewness, kurtosis, normality and serial correlation statistics. Table 1 shows that real estate and large cap stocks show negative skewness, while small cap stocks, bonds and cash all display positive skewness. Real estate, bonds and cash all showing excess kurtosis, i.e. greater than 3 , and so can not be classified as normality distributed as indicated by the Jarque-Bera test. In contrast, large and small cap stocks are normally distributed. The returns of real estate and cash also display significant $1^{\text {st }}$ order serial correlation 0.624 and 0.835 respectively.

The uncommonly low value of the risk of the real estate data, compared with government bonds, and the presence of significant $1^{\text {st }}$ order serial correlation, is a common feature of commercial real estate data; see Fisher, et al (1994) and Corgel and deRoos (1999) for comprehensive reviews. The downward bias in the second moment of real estate market indices is usually attributed to the behaviour of appraisers in conducting valuations and the temporal and cross sectional aggregation of individual real estate valuations into the market index (Geltner, 1991 and Brown and Matysiak, 1998). To account for such appraisal bias and to make the appraisal-based real estate data more comparably with the market based stock and, bond returns the real estate data was de-smoothed. The approach adopted here is to use the model suggested by Geltner (1993). However, it should be noted that no de-smoothing process is perfect and the choice of method may bias the results. In addition, the approach is sensitive to the choice of the de-smoothing parameter. The value chosen here was 0.4 as this results in a de-smoothed return series that displays an insignificant $1^{\text {st }}$ order correlation coefficient $(0.03)$ and a standard deviation of the de-smoothed real estate data about twice that of the appraisal based data, inline with the results of previous studies, see Lee and Byrne (1995). In addition, the standard deviation is approximately half that of large cap stocks (see Geltner, 1993 and Gogel and deRoos, 1999). The 50\% risk level supported in a number of surveys in both the US and UK as the 'true' risk of real estate relative to that of stocks (Hartzell and Schulman, 1988, Giliberto, 1992 and French, 1994, 1995). The effect on the mean returns of the series is also marginal. Thus, the de-smoothed real estate series used here are simulated return series after the inertia, or serial correlation, has been reduced to some acceptable level compared from the original data. This suggests that de-smoothed real estate return series is now more like market valuations. Although these returns should not be taken as actual transaction values, such prices would also reflect the liquidity of the market, and are probably reasonable estimates. The results presented in column 3 of Table 1.

Using these data the compound return of each asset and a mixed-asset portfolio was estimated using equation 1. The return contribution was then estimated using equation 3. The differences between the investments return contribution and their compound return representing the RDD. 


\section{Initial Results}

The results in Tables 2, 3, 4 and 5 show the impact to the compound returns of the mixedasset portfolio from the RDD for various holdings in real estate. Initially, a mixed-asset portfolio was constructed, without real estate and its compound return, contribution return and RDD calculated. The weightings in the various assets selected to represent a typical institutional portfolio. In particular, the mixed-asset portfolio shows an approximately a 60/40 stock/bond holding. To this mixed-asset portfolio a holding in real estate of 5\%,10\%,15\% and 20\% was added and the resultant RDD calculated. The re-allocation of the capital market assets to include real estate was done in four ways. First, the holding in real estate replaced the same percentage in the large cap stocks. In the second approach the percentage allocated to real estate replaced the same proportion in bonds. Third, real estate replaced small cap stocks. Finally, the holding in real estate was equally split between the large cap stock and bonds. In this way the impact of real estate on the mixed-asset portfolio could be evaluated under a number of scenarios.

Panel A of Tables 2, 3, 4 and 5 show that the asset class that benefits most from diversification within the mixed-asset portfolio is small cap stocks $(1.65 \mathrm{Bp})$, confirming the finds of Booth and Fama (1992). This results from the fact that small cap stocks have the highest expected return of all the asset classes. Large cap stocks, meanwhile, offers considerably less RDD as a consequence of its lower expected return and its higher correlation with the mixed-asset portfolio (0.94) compared with (0.82) for small cap stocks. Bonds meanwhile benefit very little from inclusion in the mixed-asset portfolio due to its relatively low returns, even though its correlation is only slightly positive. In contrast, a holding of 5\% in Cash generally reduces the compound returns of the mixedasset portfolio due to its low risk and return. This confirms Arnott's (1999) argument that cash is a "drag" on the performance of the mixed-asset portfolio over time. But what about direct real estate?

Table 2: The Return due to Diversification of Real Estate to the Mixed-asset Portfolio: Real Estate Replacing Bonds

\begin{tabular}{lcccccc}
\hline Asset Class & Real Estate & Large Cap & Small Cap & Bonds & Cash & Portfolio \\
\hline Portfolio Weights & $\mathbf{0 \%}$ & $\mathbf{4 5 \%}$ & $\mathbf{2 0} \%$ & $\mathbf{3 0 \%}$ & $\mathbf{5 \%}$ & $\mathbf{1 0 0 \%}$ \\
\hline Correlation with Portfolio & & $\mathbf{0 . 9 4}$ & $\mathbf{0 . 8 2}$ & $\mathbf{0 . 3 7}$ & $\mathbf{- 0 . 0 4}$ & $\mathbf{1 . 0 0}$ \\
Compound return (est.) & & $\mathbf{1 1 . 3 4}$ & $\mathbf{1 3 . 4 7}$ & $\mathbf{5 . 9 1}$ & $\mathbf{5 . 1 5}$ & $\mathbf{9 . 8 3}$ \\
Return Contribution (RC) & & $\mathbf{1 1 . 7 5}$ & $\mathbf{1 5 . 1 2}$ & $\mathbf{6 . 0 9}$ & $\mathbf{5 . 0 4}$ & $\mathbf{1 0 . 3 9}$ \\
Return due to Diversification (RDD) & & $\mathbf{0 . 4 2}$ & $\mathbf{1 . 6 5}$ & $\mathbf{0 . 1 7}$ & $\mathbf{- 0 . 1 1}$ & $\mathbf{0 . 5 6}$ \\
\hline Portfolio Weights & $\mathbf{5 \%}$ & $\mathbf{4 5 \%}$ & $\mathbf{2 0 \%}$ & $\mathbf{2 5 \%}$ & $\mathbf{5 \%}$ & $\mathbf{1 0 0 \%}$ \\
\hline Correlation with Portfolio & $\mathbf{0 . 0 8}$ & $\mathbf{0 . 9 5}$ & $\mathbf{0 . 8 4}$ & $\mathbf{0 . 3 2}$ & $\mathbf{- 0 . 0 5}$ & $\mathbf{1 . 0 0}$ \\
Compound return (est.) & $\mathbf{8 . 8 9}$ & $\mathbf{1 1 . 3 4}$ & $\mathbf{1 3 . 4 7}$ & $\mathbf{5 . 9 1}$ & $\mathbf{5 . 1 5}$ & $\mathbf{9 . 9 8}$ \\
Return Contribution (RC) & $\mathbf{9 . 1 8}$ & $\mathbf{1 1 . 7 5}$ & $\mathbf{1 5 . 1 0}$ & $\mathbf{6 . 1 1}$ & $\mathbf{5 . 0 4}$ & $\mathbf{1 0 . 5 5}$ \\
Return due to Diversification (RDD) & $\mathbf{0 . 2 9}$ & $\mathbf{0 . 4 1}$ & $\mathbf{1 . 6 3}$ & $\mathbf{0 . 2 0}$ & $\mathbf{- 0 . 1 1}$ & $\mathbf{0 . 5 7}$ \\
\hline Portfolio Weights & $\mathbf{2 0 \%}$ & $\mathbf{4 5 \%}$ & $\mathbf{2 0 \%}$ & $\mathbf{1 0 \%}$ & $\mathbf{5 \%}$ & $\mathbf{1 0 0 \%}$ \\
\hline Correlation with Portfolio & $\mathbf{0 . 2 3}$ & $\mathbf{0 . 9 5}$ & $\mathbf{0 . 8 6}$ & $\mathbf{0 . 1 6}$ & $\mathbf{- 0 . 0 7}$ & $\mathbf{1 . 0 0}$ \\
Compound return (est.) & $\mathbf{8 . 8 9}$ & $\mathbf{1 1 . 3 4}$ & $\mathbf{1 3 . 4 7}$ & $\mathbf{5 . 9 1}$ & $\mathbf{5 . 1 5}$ & $\mathbf{1 0 . 4 2}$ \\
Return Contribution (RC) & $\mathbf{9 . 0 9}$ & $\mathbf{1 1 . 7 4}$ & $\mathbf{1 5 . 0 6}$ & $\mathbf{6 . 1 8}$ & $\mathbf{5 . 0 3}$ & $\mathbf{1 0 . 9 8}$ \\
Return due to Diversification (RDD) & $\mathbf{0 . 1 9}$ & $\mathbf{0 . 4 1}$ & $\mathbf{1 . 5 9}$ & $\mathbf{0 . 2 7}$ & $\mathbf{- 0 . 1 2}$ & $\mathbf{0 . 5 6}$ \\
\hline
\end{tabular}


Table 3: The Return due to Diversification of Real Estate to the Mixed-asset Portfolio: Real Estate Replacing Large Cap Stocks

\begin{tabular}{lcccccc}
\hline Asset Class & Real Estate & Large Cap Small Cap & Bonds & Cash & Portfolio \\
\hline Portfolio Weights & $\mathbf{0}$ & $\mathbf{4 5 \%}$ & $\mathbf{2 0 \%}$ & $\mathbf{3 0 \%}$ & $\mathbf{5 \%}$ & $\mathbf{1 0 0 \%}$ \\
\hline Correlation with Portfolio & & $\mathbf{0 . 9 4}$ & $\mathbf{0 . 8 2}$ & $\mathbf{0 . 3 7}$ & $\mathbf{- 0 . 0 4}$ & $\mathbf{1 . 0 0}$ \\
Compound return (est.) & & $\mathbf{1 1 . 3 4}$ & $\mathbf{1 3 . 4 7}$ & $\mathbf{5 . 9 1}$ & $\mathbf{5 . 1 5}$ & $\mathbf{9 . 8 3}$ \\
Return Contribution (RC) & & $\mathbf{1 1 . 7 5}$ & $\mathbf{1 5 . 1 2}$ & $\mathbf{6 . 0 9}$ & $\mathbf{5 . 0 4}$ & $\mathbf{1 0 . 3 9}$ \\
Return due to Diversification (RDD) & & $\mathbf{0 . 4 2}$ & $\mathbf{1 . 6 5}$ & $\mathbf{0 . 1 7}$ & $\mathbf{- 0 . 1 1}$ & $\mathbf{0 . 5 6}$ \\
\hline Portfolio Weights & $\mathbf{5 \%}$ & $\mathbf{4 0 \%}$ & $\mathbf{2 0 \%}$ & $\mathbf{3 0 \%}$ & $\mathbf{5 \%}$ & $\mathbf{1 0 0 \%}$ \\
\hline Correlation with Portfolio & $\mathbf{0 . 0 6}$ & $\mathbf{0 . 9 4}$ & $\mathbf{0 . 8 3}$ & $\mathbf{0 . 3 7}$ & $\mathbf{- 0 . 0 3}$ & $\mathbf{1 . 0 0}$ \\
Compound return (est.) & $\mathbf{8 . 8 9}$ & $\mathbf{1 1 . 3 4}$ & $\mathbf{1 3 . 4 7}$ & $\mathbf{5 . 9 1}$ & $\mathbf{5 . 1 5}$ & $\mathbf{9 . 7 1}$ \\
Return Contribution (RC) & $\mathbf{9 . 2 0}$ & $\mathbf{1 1 . 8 2}$ & $\mathbf{1 5 . 1 8}$ & $\mathbf{6 . 1 0}$ & $\mathbf{5 . 0 5}$ & $\mathbf{1 0 . 3 1}$ \\
Return due to Diversification (RDD) & $\mathbf{0 . 3 1}$ & $\mathbf{0 . 4 8}$ & $\mathbf{1 . 7 1}$ & $\mathbf{0 . 1 9}$ & $\mathbf{- 0 . 1 1}$ & $\mathbf{0 . 6 0}$ \\
\hline Portfolio Weights & $\mathbf{2 0 \%}$ & $\mathbf{2 5 \%}$ & $\mathbf{2 0 \%}$ & $\mathbf{3 0 \%}$ & $\mathbf{5 \%}$ & $\mathbf{1 0 0} \%$ \\
\hline Correlation with Portfolio & $\mathbf{0 . 2 1}$ & $\mathbf{0 . 9 0}$ & $\mathbf{0 . 8 3}$ & $\mathbf{0 . 3 6}$ & $\mathbf{0 . 0 1}$ & $\mathbf{1 . 0 0}$ \\
Compound return (est.) & $\mathbf{8 . 8 9}$ & $\mathbf{1 1 . 3 4}$ & $\mathbf{1 3 . 4 7}$ & $\mathbf{5 . 9 1}$ & $\mathbf{5 . 1 5}$ & $\mathbf{9 . 3 4}$ \\
Return Contribution (RC) & $\mathbf{9 . 1 7}$ & $\mathbf{1 2 . 0 1}$ & $\mathbf{1 5 . 3 9}$ & $\mathbf{6 . 1 5}$ & $\mathbf{5 . 0 5}$ & $\mathbf{1 0 . 0 1}$ \\
Return due to Diversification (RDD) & $\mathbf{0 . 2 8}$ & $\mathbf{0 . 6 7}$ & $\mathbf{1 . 9 2}$ & $\mathbf{0 . 2 4}$ & $\mathbf{- 0 . 1 0}$ & $\mathbf{0 . 6 7}$ \\
\hline
\end{tabular}

Table 4: The Return due to Diversification of Real Estate to the Mixed-asset Portfolio: Real Estate Replacing Small Cap Stocks

\begin{tabular}{lcccccc}
\hline Asset Class & Real Estate Large Cap Small Cap & Bonds & \multicolumn{2}{c}{ Cash } & Portfolio \\
\hline Portfolio Weights & $\mathbf{0}$ & $\mathbf{4 5 \%}$ & $\mathbf{2 0 \%}$ & $\mathbf{3 0 \%}$ & $\mathbf{5 \%}$ & $\mathbf{1 0 0 \%}$ \\
\hline Correlation with Portfolio & & $\mathbf{0 . 9 4}$ & $\mathbf{0 . 8 2}$ & $\mathbf{0 . 3 7}$ & $\mathbf{- 0 . 0 4}$ & $\mathbf{1 . 0 0}$ \\
Compound return (est.) & & $\mathbf{1 1 . 3 4}$ & $\mathbf{1 3 . 4 7}$ & $\mathbf{5 . 9 1}$ & $\mathbf{5 . 1 5}$ & $\mathbf{9 . 8 3}$ \\
Return Contribution (RC) & & $\mathbf{1 1 . 7 5}$ & $\mathbf{1 5 . 1 2}$ & $\mathbf{6 . 0 9}$ & $\mathbf{5 . 0 4}$ & $\mathbf{1 0 . 3 9}$ \\
Return due to Diversification (RDD) & & $\mathbf{0 . 4 2}$ & $\mathbf{1 . 6 5}$ & $\mathbf{0 . 1 7}$ & $\mathbf{- 0 . 1 1}$ & $\mathbf{0 . 5 6}$ \\
\hline Portfolio Weights & $\mathbf{5 \%}$ & $\mathbf{4 5 \%}$ & $\mathbf{1 5 \%}$ & $\mathbf{3 0 \%}$ & $\mathbf{5 \%}$ & $\mathbf{1 0 0 \%}$ \\
\hline Correlation with Portfolio & $\mathbf{0 . 0 7}$ & $\mathbf{0 . 9 5}$ & $\mathbf{0 . 7 8}$ & $\mathbf{0 . 3 9}$ & $\mathbf{- 0 . 0 3}$ & $\mathbf{1 . 0 0}$ \\
Compound return (est.) & $\mathbf{8 . 8 9}$ & $\mathbf{1 1 . 3 4}$ & $\mathbf{1 3 . 4 7}$ & $\mathbf{5 . 9 1}$ & $\mathbf{5 . 1 5}$ & $\mathbf{9 . 6 0}$ \\
Return Contribution (RC) & $\mathbf{9 . 2 1}$ & $\mathbf{1 1 . 8 3}$ & $\mathbf{1 5 . 2 6}$ & $\mathbf{6 . 1 0}$ & $\mathbf{5 . 0 5}$ & $\mathbf{1 0 . 1 5}$ \\
Return due to Diversification (RDD) & $\mathbf{0 . 3 1}$ & $\mathbf{0 . 4 9}$ & $\mathbf{1 . 7 9}$ & $\mathbf{0 . 1 9}$ & $\mathbf{- 0 . 1 0}$ & $\mathbf{0 . 5 6}$ \\
\hline Portfolio Weights & $\mathbf{2 0 \%}$ & $\mathbf{4 5 \%}$ & $\mathbf{0 \%}$ & $\mathbf{3 0 \%}$ & $\mathbf{5 \%}$ & $\mathbf{1 0 0 \%}$ \\
\hline Correlation with Portfolio & $\mathbf{0 . 2 3}$ & $\mathbf{0 . 9 3}$ & & $\mathbf{0 . 4 8}$ & $\mathbf{0 . 0 0}$ & $\mathbf{1 . 0 0}$ \\
Compound return (est.) & $\mathbf{8 . 8 9}$ & $\mathbf{1 1 . 3 4}$ & & $\mathbf{5 . 9 1}$ & $\mathbf{5 . 1 5}$ & $\mathbf{8 . 9 1}$ \\
Return Contribution (RC) & $\mathbf{9 . 2 0}$ & $\mathbf{1 2 . 0 5}$ & & $\mathbf{6 . 1 3}$ & $\mathbf{5 . 0 7}$ & $\mathbf{9 . 3 6}$ \\
Return due to Diversification (RDD) & $\mathbf{0 . 3 1}$ & $\mathbf{0 . 7 2}$ & & $\mathbf{0 . 2 2}$ & $\mathbf{- 0 . 0 8}$ & $\mathbf{0 . 4 5}$ \\
\hline
\end{tabular}

Table 5: The Return due to Diversification of Real Estate to the Mixed-asset Portfolio: Real Estate Replacing Large Cap Stocks/Bonds

\begin{tabular}{lcccccc}
\hline Asset Class & Real Estate & Large Cap Small Cap & Bonds & \multicolumn{2}{c}{ Cash } & Portfolio \\
\hline Portfolio Weights & $\mathbf{0}$ & $\mathbf{4 5 \%}$ & $\mathbf{2 0 \%}$ & $\mathbf{3 0 \%}$ & $\mathbf{5 \%}$ & $\mathbf{1 0 0 \%}$ \\
\hline Correlation with Portfolio & & $\mathbf{0 . 9 4}$ & $\mathbf{0 . 8 2}$ & $\mathbf{0 . 3 7}$ & $\mathbf{- 0 . 0 4}$ & $\mathbf{1 . 0 0}$ \\
Compound return (est.) & & $\mathbf{1 1 . 3 4}$ & $\mathbf{1 3 . 4 7}$ & $\mathbf{5 . 9 1}$ & $\mathbf{5 . 1 5}$ & $\mathbf{9 . 8 3}$ \\
Return Contribution (RC) & & $\mathbf{1 1 . 7 5}$ & $\mathbf{1 5 . 1 2}$ & $\mathbf{6 . 0 9}$ & $\mathbf{5 . 0 4}$ & $\mathbf{1 0 . 3 9}$ \\
Return due to Diversification (RDD) & & $\mathbf{0 . 4 2}$ & $\mathbf{1 . 6 5}$ & $\mathbf{0 . 1 7}$ & $\mathbf{- 0 . 1 1}$ & $\mathbf{0 . 5 6}$ \\
\hline Portfolio Weights & $\mathbf{5 \%}$ & $\mathbf{4 3 \%}$ & $\mathbf{2 0 \%}$ & $\mathbf{2 8 \%}$ & $\mathbf{5 \%}$ & $\mathbf{1 0 0 \%}$ \\
\hline Correlation with Portfolio & $\mathbf{0 . 0 7}$ & $\mathbf{0 . 9 4}$ & $\mathbf{0 . 8 3}$ & $\mathbf{0 . 3 4}$ & $\mathbf{- 0 . 0 4}$ & $\mathbf{1 . 0 0}$ \\
Compound return (est.) & $\mathbf{8 . 8 9}$ & $\mathbf{1 1 . 3 4}$ & $\mathbf{1 3 . 4 7}$ & $\mathbf{5 . 9 1}$ & $\mathbf{5 . 1 5}$ & $\mathbf{9 . 8 4}$ \\
Return Contribution (RC) & $\mathbf{9 . 1 9}$ & $\mathbf{1 1 . 7 8}$ & $\mathbf{1 5 . 1 4}$ & $\mathbf{6 . 1 1}$ & $\mathbf{5 . 0 4}$ & $\mathbf{1 0 . 4 3}$ \\
Return due to Diversification (RDD) & $\mathbf{0 . 3 0}$ & $\mathbf{0 . 4 5}$ & $\mathbf{1 . 6 7}$ & $\mathbf{0 . 1 9}$ & $\mathbf{- 0 . 1 1}$ & $\mathbf{0 . 5 9}$ \\
\hline Portfolio Weights & $\mathbf{2 0 \%}$ & $\mathbf{3 5 \%}$ & $\mathbf{2 0 \%}$ & $\mathbf{2 0 \%}$ & $\mathbf{5 \%}$ & $\mathbf{1 0 0 \%}$ \\
\hline Correlation with Portfolio & $\mathbf{0 . 2 2}$ & $\mathbf{0 . 9 3}$ & $\mathbf{0 . 8 5}$ & $\mathbf{0 . 2 5}$ & $\mathbf{- 0 . 0 4}$ & $\mathbf{1 . 0 0}$ \\
Compound return (est.) & $\mathbf{8 . 8 9}$ & $\mathbf{1 1 . 3 4}$ & $\mathbf{1 3 . 4 7}$ & $\mathbf{5 . 9 1}$ & $\mathbf{5 . 1 5}$ & $\mathbf{9 . 8 8}$ \\
Return Contribution (RC) & $\mathbf{9 . 1 3}$ & $\mathbf{1 1 . 8 7}$ & $\mathbf{1 5 . 2 3}$ & $\mathbf{6 . 1 7}$ & $\mathbf{5 . 0 4}$ & $\mathbf{1 0 . 5 1}$ \\
Return due to Diversification (RDD) & $\mathbf{0 . 2 4}$ & $\mathbf{0 . 5 4}$ & $\mathbf{1 . 7 6}$ & $\mathbf{0 . 2 6}$ & $\mathbf{- 0 . 1 1}$ & $\mathbf{0 . 6 3}$ \\
\hline
\end{tabular}


Panels $\mathrm{B}$ and $\mathrm{C}$ of Tables 2, 3, 4, and 5 shows that real estate generally offers increased RDD to the mixed-asset portfolio. However, the benefit depends upon which asset is replaced and the percentage allocation to real estate ${ }^{3}$. For instance, without real estate the RDD of the four capital market assets (large cap stocks, small cap stocks, bonds and cash) is $56 \mathrm{Bp}$, however, when $5 \%$ in real estate replaces the same amount in large cap stocks this increases to $60 \mathrm{Bp}$ an increase of $4 \mathrm{Bp}$. However, the increase is only $3 \mathrm{Bp}$ when the holding in real estate is equally split between large cap stocks and bonds and only $1 \mathrm{Bp}$ when real estate replaces bonds. While, a $5 \%$ holding in real estate at the expense of small cap stocks as no effect on the RDD.

The other noticeable feature of Tables 2 to 5 is that as the percentage holding in real estate increases the RDD rises or falls depending on the asset class replaced. For instance, a 20\% holding in real estate, replacing large cap stocks shows an increase in the $\mathrm{RDD}$ of $11 \mathrm{Bp}$ compared with $4 \mathrm{Bp}$ at the $5 \%$ level. A similar conclusion can be dbserved when real estate is substituted for large cap stocks/bonds, 7Bp compared with 3Bp. In contrast, increasing the holding in real estate at the expense of bonds initially leads to a rise in RDD that falls back to zero at the $20 \%$ level. In contrast, any increase in the holdings in real estate at the cost of small cap stocks leads to a fall in the RDD of the mixed-asset portfolio.

This implies that when real estate replaces large cap stocks or large cap stocks/bonds the impact on the RDD of the mixed-asset portfolio is always beneficial. Whereas, when real estate replaces bonds the increase in returns due to diversification is negligible, while any holding in real estate at the expense of small cap stocks is detrimental. In other words, a $20 \%$ allocation to real estate, which typically the suggested in the literature (see Hoesli et al, 2001 and Seiler et al, 1999) is only justifiable when real estate replaces large cap stocks or large cap stocks/bonds.

\section{Confidence Limits}

Equations 1 and 3 show that the compound return, the return contribution and the RDD depend solely on estimates of the mean, standard deviation and the covariance between the investment and the portfolio. The results presented in Tables 2 to 5, however, are only point estimates drawn from the sampled returns data, consequently we cannot infer whether the results presented are representative of the likely outcome over sampling different periods. In other words, how confident can we be that the results so far are representative of the benefits of including real estate in the mixed-asset portfolio in the long run?

To overcome this the return series were bootstrapped to generate a simulated ex ante return series to provide a confidence limit around the mean. The assumption being that the ex ante returns of any asset are random variations of its ex post returns with the same contemporaneous structure as the original data. This flexibility permits a more detailed assessment of the effects of including real estate in the mixed-asset portfolio. In the real

\footnotetext{
3 The results for $10 \%$ and $15 \%$ in real estate have been removed for brevity but are available upon request.
} 
estate research, several studies have applied this kind of analysis (see Liang et al, 1996, Ziobrowski et al, 1997 and Hardin and Cheng, 2002).

The bootstrap method provides a convenient method of estimating the sample distribution of a random variable by repeatedly sampling, with replacement, from the original data set (Efron, 1979 and Efron and Tibshirani, 1986). However, while the bootstrap method generally produces robust results, the technique is subject to two potential problems. First, as a purely statistical technique the method ignores economic fundament principles, such as the tendency for markets to converge to equilibrium. Therefore, to avoid this problem the data should be long enough to include at least one complete cycle br such information to be present in the ex post data and so be preserved in the simulated series. As we use data from such a long period (1951-2001) this is unlikely to present a problem. A second and potential a more serious problem is that if the data are auto-correlated, directly re-sampling the original data will destroy its contemporaneous structure. Therefore, in order to maintain the any autocorrelation structure in the data series a Vector Auto Regression (VAR) procedure was applied by the following equation:

$$
\mathrm{V}_{\mathrm{t}}=\mathrm{C}^{\prime} \mathrm{V}_{\mathrm{t}-1}+\varepsilon_{\mathrm{t}}
$$

Where $\mathrm{V}_{\mathrm{t}}$ and $\mathrm{V}_{\mathrm{t}-1}$ are vectors of the time series data of the asset classes at time $\mathrm{t}$ and $\mathrm{t}-1$, $\mathrm{C}$ is the coefficient matrix and $\varepsilon_{\mathrm{t}}$ is the error term matrix. Equation 4 is limited to a first order auto regression model as most of the serial dependence in the series can be captured by the first lag. The error term matrix represents the random components of the sampled data and it is the random component that is bootstrapped in the simulation process. This re-sampled return series was then use to generate all the statistics needed to calculate the RDD of the mixed-asset portfolio. The process was then repeated 10,000 times with this bootstrap distribution taken to represent the sampling distribution of the data. The median and the $2.5 \%$ and $97.5 \%$ percentiles of the bootstrap distribution were then computed. These percentile levels chosen as they represent the 95\% confidence limit around the median, the results presented in Table 6.

Table 6: The Gain/loss in Return due to Diversification from including Real Estate in the Mixed-Asset Portfolio Compared with a Portfolio without Real Estate

\begin{tabular}{lcccc}
\hline RE Replacing & Bonds & Large Cap & Small Cap & L Cap/Bonds \\
\hline $\mathbf{p}=2.5 \%$ & 1.64 & 3.52 & 0.27 & 2.74 \\
$5 \%$ & 2.57 & 6.56 & -0.46 & 4.76 \\
$10 \%$ & 2.44 & 9.15 & -3.58 & 6.35 \\
$15 \%$ & 1.49 & 10.40 & -8.00 & 7.29 \\
$20 \%$ & & & & \\
P=50\% & 0.67 & 3.96 & -0.88 & 2.47 \\
$5 \%$ & 1.06 & 7.13 & -2.90 & 4.61 \\
$10 \%$ & 0.88 & 9.64 & -6.49 & 5.96 \\
$15 \%$ & -0.06 & 11.47 & -11.65 & 7.13 \\
$20 \%$ & & & & \\
p=97.5\% & 1.45 & 3.86 & 0.34 & 2.85 \\
$5 \%$ & 2.53 & 6.97 & -1.10 & 4.91 \\
$10 \%$ & 2.22 & 9.41 & -4.18 & 6.31 \\
$15 \%$ & 1.41 & 10.84 & -8.80 & 7.55 \\
$20 \%$ & & & & \\
\hline
\end{tabular}


Table 6 shows that including 5\% real estate at the expense of bonds, large cap stocks and large cap stocks/bonds increases the average (median) RDD of the mixed-asset portfolio from a low of $0.7 \mathrm{bp}$ (bonds) to a high of $4 \mathrm{bp}$ (large cap stocks). This increase in RDD continues when the holding in real estate is increased up to $20 \%$ at the expanse of large cap stocks or large cap/bonds. However, when real estate replaces bonds the impact initially rises then falls as the holding in real estate is increased to $20 \%$. In contrast, a $5 \%$ holding in real estate replacing small cap stocks leads to a fall in the RDD of $0.9 \mathrm{bp}$, a reduction that continues the greater the holding in real estate. In other words, including real estate doesn't automatically increase the RDD of the mixed asset portfolio. The impact depends on the asset class replaced and the allocation to real estate, results in line with those in Tables 2-5.

The results for lower 95\% confidence limit are more encouraging. A 5\% holding in real estate leads to an increase in the RDD of the mixed-asset portfolio for all asset classes replaced from a low of $0.3 \mathrm{bp}$ (small cap stocks) to a high of $3.5 \mathrm{bp}$ (large cap stocks). In contrast, larger holdings in small cap stocks lead to a lowering of the RDD. This implies that larger holdings real estate generally increases the likelihood that the compound return, or terminal wealth, of the mixed-asset portfolio will be greater than that of a portfolio without real estate even in the worse case scenario, except when the real estate replaces small cap stocks. The upper $95 \%$ confidence limit provides similar results.

\section{Conclusions}

Booth and Fama (1992) observe that the compound return of a portfolio is greater than the weighted average of the compound returns of the individual investments. This counterintuitive result stems from the fact that although variance is an appropriate measure of risk of a portfolio it is not he relevant measure of the risk of the investment within a portfolio. The risk of an investment within a portfolio should be measured by its covariance with the portfolio. This difference between an investments individual compound return and its contribution to the compound return of a portfolio is referred to as the "return due to diversification". Thus assets that have a low covariance with a mixed-asset portfolio may be more desirable, in terms of the compound return of the portfolio, than an asset with a high covariance. Real estate is an asset class that displays such an investment characteristic with the mixed-asset portfolio. Hence, a holding in real estate, higher than that observed in practice, may be justified by its contribution to the compound returns of the mixed-asset portfolio from its RDD. This paper has tested this proposition using annual data for the five asset classes; real estate, large cap stocks, small cap stocks, bonds and cash over the period 1951-2001. The results show that a holding in real estate can increases the compound return of the mixed-asset portfolio above that of an existing portfolio composed of the other asset classes. However, the results are dependent on the percentage allocation to real estate and the asset class replaced. Nonetheless, the justification for including real estate in the mixed-asset portfolio need not rest on its diversification benefits alone but can be made on its contribution to the compound return, or terminal wealth, of the fund from which he institution will meet its future obligations. 


\section{References}

Arnott, R.D. (1995) Investment Strategy, in The Portable MBA in Investment, ed. P.L. Bernstein, New York, Wiley

Brinson, G.P., Hood, L.R. and Beebower, G.L. (1986) Determinants of Portfolio Performance, Financial Analysts Journal, 42, 4, July/August, 39-44

Brinson, G.P., Hood, L.R. and Singer, R. (1991) Determinants of Portfolio Performance II: An Update, Financial Analysts Journal, 47, 3, May/June, 40-48

Byrne, P.J. and Lee, S.L. (1995) Is There a Place for Property in the Multiasset Portfolio? Journal of Property Finance, 6, 3, 60-83

Brown, G.R. and Matysiak, G.A. (1998) Valuation Smoothing without Temporal Aggregation, Journal of Property Research, 15, 89-103

Booth, D.G. and Fama, E.F. (1992) Diversification Returns and Asset Contributions, Financial Analysts Journal, 48, May-June, 26-32

Corgel, J.B. and deRoos, J.A. (1999) Recovery of Real Estate Returns for Portfolio Allocation, Journal of Real Estate Finance and Economics, 18, 279-296

Efron, B (1979) Bootstrap Methods: Another Look at the Jackknife, Annals of Statistics, 7, 1-26.

Efron, B and Tibshirani, R. (1986) Bootstrap Methods for Statistical Standard Errors, Confidence Intervals and Other Measures of Statistical Accuracy, Statistical Science, 1, 54-77

Fisher, J.D., Geltner, D.M. and Webb, R.B. (1994) Value Indices of Commercial Real Estate: A Comparison of Index Construction Methods, Journal of Real Estate Finance and Economics, 9, 137-164

French, N. (1994) Property in the Context of Multi-asset Portfolios (The UK Experience), A Paper given at The European Real Estate Society Conference, Amsterdam, Holland, November

French, N. (1995) Property - love it or leave it? Estates Gazette, 9540, 126-127

Giliberto, M. (1992) Real Estate Risk and Return: 1991 Survey Results, Real Estate Research paper, Salomon Brothers Inc., March 1992

Geltner, D.M. (1991) Smoothing in Appraisalbased Returns, Journal of Real Estate Finance and Economics, 4, 327-345 
Geltner, D.M. (1993) Estimating Market Values from Appraised Values without Assuming an Efficient Market, Journal of Real Estate Research, 8, 325-345

Hartzell, D. and Schulman, D.G. (1988) Real Estate Returns and Risks: a Survey, Salomon Brothers Inc, February 121988

Hoesli, M., MacGregor, B., Adair, A. and McGreal, S. (2001) The Role of Property in Mixed Asset Portfolios (MAPs), RICS Foundation, RS0201

Hudson-Wilson, S. and Hopkins, R.E. Jr. (2002) Why Real Estate? Chapter 1, in Modern Real Estate Portfolio Management, ed. S. Hudson-Wilson, Frank J. Fabozzi Associates

Ibbotson Associates (2002) Stocks, Bonds, Bills and Inflation, 2002 Yearbook, Ibbotson Associates Inc

Kaiser, R.W. (1997) Long Cycles in Real Estate, Journal of Real Estate Research, 14, 3, 233-258

Lee, S., Byrne, P.J. and French, N.S. (1996) Assessing the Future of Property in the Multi-asset Portfolio: the Case of UK Pension Funds, Journal of Property Research, 13, 3, 197-209

Radcliffe, R.C. (1994) Investment: Concepts, Analysis, Strategy, New York, Harper Collins

Seiler, M.J., Webb, J.R. and Myer, F.C.N. (1999) Diversification Issues in Real estate Investment, Journal of Real Estate Literature, 7, 2, 163-179 